authority employs imprisonment, torture, or murder against scholars who stray beyond restrictions on inquiry or expression?

There may be circumstances in which international higher education partnerships cannot be maintained in good faith: for example where formal apartheid-type systems are in place or where genocidal violence is occurring. But situations warranting a full withdrawal are infrequent. Circumstances are almost always complex and changing, and there is a strong perspective in international higher education that favors more exchange, not less. Academic communities must not allow this perspective to support their silence in the face of wrongdoing by their partners. To do so is at least tacitly to acquiesce.

There may be circumstances in which international higher education partnerships cannot be maintained in good faith.

Fortunately, silence is not the only option. Academic communities can work together to promote a cross-cultural dialogue that addresses the importance of academic freedom, its scope and boundaries, and steps that might be taken to ensure academic freedom is understood and respected.

One way to start this dialogue would be for every international higher education partnership (faculty or student exchanges, for example) to acknowledge the role of academic freedom in the relationship. A joint statement of understanding might address the responsibilities of faculty, administration, and students of the partner institutions in exercising, promoting, and respecting academic freedom and might include provisions for raising concerns about academic freedom issues. Through such simple measures significant improvements in understanding and local conditions might be achieved. Another way to start this dialogue would be to hold events focused on academic freedom and threats to scholarly communities. Introducing these issues to colleagues, students, media, and members of the public can expand the dialogue and magnify its effect.

Of course when scholars are presently suffering intimidation and attack, promoting understanding and organizing events are not enough. Action must be taken. Letters from higher education leaders put wrongdoers on notice that the world is watching. Joint-letters from groups of higher education communities are even more powerful in showing that concern about violations is widespread.

For the most severely threatened scholars, however, even letters are not enough-refuge is essential if their voices are to be saved. Academic communities can make room on their campuses and in their classrooms for these individuals. By lending shelter and safety for a short time, academic communities give these scholars a chance to recover, regroup, and resume their work.

Of course, no one community can be expected to do it all. A collective response is necessary. Since 2000, the Scholars at Risk Network has provided that response. Scholars at Risk is an international network of more than 80 colleges and universities dedicated to promoting academic freedom and defending the human rights of scholars worldwide. Institutions of higher education in any country can join the Network. Some members send letters of concern about particular violations of academic freedom; others host events on their campuses featuring formerly threatened or exiled scholars. In the last four years, dozens have invited threatened scholars to be visitors at their campuses for up to a year or more, during which time the scholars lecture, do research, and write. These visits have saved many important voices and dozens of lives, including most of those mentioned at the beginning of this essay.

What is most important is that academic communities share responsibility and join in the growing dialogue about the importance of academic freedom. Such actions will not only help to achieve added protections for threatened individuals but will ensure that international higher education maintains its essential core of freedom, allowing it to deliver on its promise of a brighter, more prosperous, and more peaceful future for all.

\section{GATS Update}

\section{Madeleine F. Green}

Madeleine F. Green is vice president and director of the Center for Institutional and International Initiatives at the American Council on Education (ACE). Address: American Council on Education, One Dupont Circle N.W., Washington D.C. 20036, USA. E-mail: Madeleine_Green@ace.nche.edu. A longer version of this paper is available on the ACE website http://acenet.edu/programs/international/ gats/2004-update.cfm.

The inclusion of higher education in the General 1 Agreement of Trade in Services (GATS) continues to concern higher education leaders, students, and faculty around the world. They fear that liberalization of trade in education may weaken governments' commitment to and investment in public higher education, promote privatization, and put countries with weak quality assurance mechanisms at a disadvantage in their efforts to oversee education programs delivered in their countries by foreign providers. 


\section{Commitments, Offers, and Requests: A Tally}

Negotiations are conducted as a series of requests and offers. Each WTO member submits requests to individual trading partners or to groups of members. Members may then choose to respond by submitting offers; they also decide whether to make their requests and offers public. Because requests are usually handled bilaterally rather than through any central mechanism, no complete list of requests exists. Some requests have been leaked, but they cannot be verified.

\section{Forty-four members made commitments in education in the previous round of negotia- tions.}

Forty-four members made commitments in education in the previous round of negotiations (the "Uruguay round"), which ended in 1995; of these, 21 included commitments in higher education. The current requests and offers will only become solid commitments at the end of the current ("Doha") round. The Doha round is supposed to end January 1, 2005, but slow negotiations may cause that deadline to be extended.

It is not known how many of the 145 WTO members have made initial requests in education, because requests are not made public. Some requests in higher education have been leaked, such as those that the United States made of the European Union, Mexico, and Brazil and the EU requests of 109 nations. In addition, some members have made summaries of their requests public. Forty-four members had submitted offers as of July 2004, including nine in education. Many negotiations are taking place outside the GATS framework, in bilateral discussions (such as between the United States and Australia).

\section{U.S. Engagement in the GATS Negotiations}

Four nations-the United States, Australia, Japan, and New Zealand-put forth negotiating proposals. The U.S. negotiating proposal (December 2000) affirms the rights of governments to regulate in order to meet domestic policy objectives, acknowledges that governments will continue to play important roles as service suppliers, and emphasizes benefits to the receiving country-for example, help in upgrading its workforce and improving its competitiveness. (See http:/ / www.wto.org/english/ tratop_e/serv_e/s_propnewnegs_e.htm.)

The United States has released a summary of its July 2002 request, seeking increased access for higher education, training services, and testing services. (See http: / / ustr.gov / sectors / services / 2002-07-01- proposal-execsumm.pdfo) The request asked that all 145 WTO members undertake full commitments for market access and national treatment in modes 1,2 , and 3 . The four modes of supply are: mode 1 : cross-border supply (e.g., distance learning); mode 2: consumption abroad (e.g., study abroad); mode 3: commercial presence (e.g., branch campuses or arrangements with local institutions); and mode 4: presence of natural persons (professors or researchers working abroad). The United States indicated that it was not requesting commitments in primary or secondary education, nor commitments with respect to public education or subsidies.

In addition to this general request, leaked information indicates that the United States has made requests of a number of countries-including Taiwan, Egypt, India, Mexico, Philippines, Thailand, El Salvador, Turkey, China, Israel, Japan, South Africa, Greece, Italy, Ireland, Spain, and Sweden-to remove specific barriers.

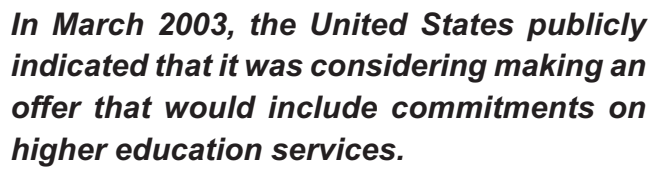

In March 2003, the United States publicly indicated that it was considering making an offer that would include commitments on higher education services. The text, which is available on the U.S. Trade Representative website (http: / / www.ustr.gov/ sectors/ services/200303-31-consolidated_offer.pdf) outlines a number of limitations on potential commitments. Observers have noted the contrast between the ambitious nature of the U.S. request and the very explicit limitations to the U.S. offer. Among the limitations to a possible U.S. commitment on higher education are the following: the ability of individual U.S. institutions to maintain autonomy in admissions policies, setting tuition rates, developing curricula or course content; the granting of U.S. federal or state government funding or subsidies to U.S. schools or citizens; the requirements for regional or specialty accreditation practices; and the conditions for foreign-owned entities to receive public benefits.

\section{Continuing Concerns about GATS}

The topic of GATS negotiations in higher education has generated more heated discussion and speculation than analysis and forecasting. This is not surprising, given that GATS is an untested instrument and the outcomes are difficult to project. A number of concerns have surfaced over time. 
"Tradespeak." Not surprisingly, the world of trade uses a different conceptual framework and is underpinned by a different set of values from those of higher education. Philip Altbach and others have written about the dangers of considering higher education as simply another service to be traded, rather than as an investment in a nation's social, cultural, and economic development.

Representation of higher education. Trade negotiations are by nature not a transparent process. Governments negotiate on behalf of the services represented in GATS. Countries have varied widely in their approach to soliciting the views of the higher education community to inform and guide their GATS positions.

Governments negotiate on behalf of the services represented in GATS.

Unintended consequences. Higher education leaders are in the difficult position of being unable to anticipate the variety of scenarios that could unfold. Higher education groups in several countries (e.g., Canada, the United States, and Switzerland) have commissioned analyses by trade and legal experts, but they have provided few definitive answers at this point.

Ambiguity about GATS. Article 1.3 of the GATS agreement indicates that "services supplied in the exercise of governmental authority," supplied on a "noncommercial basis," and those "not in competition with other suppliers" are excluded from GATS. In a mixed public-private system, how would GATS deal with the distinctions among public, private nonprofit, and for-profit institutions? What precisely does it mean to be "not in competition with other suppliers"? The ambiguity surrounding article 1.3 has been noted in much of the literature about GATS, with no clear resolution.

Trade-offs in continuing negotiations. Limitations on offers are not cast in stone. As the negotiations proceed, members request progressive trade-offs, either within a sector such as education or across service sectors. For example, a country could make concessions in education in order to gain concessions from another country in express delivery. The principle of progressive liberalization suggests steadily removing limitations that act as barriers.

Impact on higher education in developing countries. Many developing countries lack sufficiently robust quality assurance systems to regulate foreign providers adequately, and thus protect consumers. Additionally, many developing countries see liberalization of trade as a threat to their public higher education systems. If foreign providers establish programs in areas requiring relatively little capital investment, such as business or information technology, the local public institutions will be left with the more expensive programs, such as engineering and the sciences, without the lower-cost programs to subsidize the higher-cost ones.

\section{The Search for International Consensus}

It is important to note that opposition to or reservations about including higher education in GATS negotiations does not equal opposition to cross-border education. There is widespread recognitions of the benefits of cross-border education and its potential to provide higher education capacity to nations whose demand outstrips supply. In recognition of the importance of cross-border education, four higher education associations (the American Council on Education, the Council on Higher Education Accreditation, the Association of Universities and Colleges of Canada, and the International Association of Universities) have drafted a statement, "Sharing Quality Higher Education Across Borders: A statement on Behalf of Higher Education Institutions Worldwide." The statement, addressed to higher education institutions and their nongovernmental associations worldwide and to their national governments and their intergovernmental organizations, aims to create an international consensus on a fair and transparent framework for managing higher education across borders. It outlines principles that should underpin cross-border education and government policies in trade negotiations and suggests specific actions that reinforce those principles. The document is on the websites of all four drafting organizations (www.acenet.edu/programs/international/ sharing_quality/statement.cfm) and will be open for comment through September 2004. At the end of the consultation period, the document will then be finalized and circulated for signature by higher education associations.

\section{GATS Redux: The WTO and Higher Education Returns to Center Stage \\ Philip G. Altbach}

Philip G. Altbach is J. Donald Monan SJ professor of higher education and director of the Center for International Higher Education at Boston College.

With the collapse of the WTO's Cancun trade talks a year ago amidst recriminations between developing countries and others concerning agricultural exports and other issues, treaty negotiations were pushed to the back burner. Trade discussions moved to the regional and 